\begin{tabular}{|c|c|c|}
\hline \multirow{3}{*}{$\begin{array}{l}\text { EREM 74/4 } \\
\text { Journal of Environmental Research, } \\
\text { Engineering and Management } \\
\text { Vol. 74 / No. } 4 \text { / } 2018 \\
\text { pp. 43-52 } \\
\text { DOl 10.5755/j01.erem.74.4.20893 } \\
\text { @ Kaunas University of Technology }\end{array}$} & \multicolumn{2}{|c|}{$\begin{array}{l}\text { Differences Between Aronia Medik. Taxa on the } \\
\text { Morphological and Biochemical Characters }\end{array}$} \\
\hline & Received 2018/06 & Accepted after revision 2018/10 \\
\hline & \multicolumn{2}{|c|}{ Crossef http://dx.doi.org/10.5755/j01.erem.74.4.20893 } \\
\hline
\end{tabular}

\title{
Differences Between \\ Aronia Medik. Taxa on \\ the Morphological and \\ Biochemical Characters
}

\section{Yulia Vinogradova, Olga Shelepova}

Main Botanical Garden Russian Academy of Sciences, Botanicheskaya 4, 127276 Moscow, Russia

\section{Olena Vergun, Olga Grygorieva}

M.M. Gryshko National Botanical Gardens of Ukraine National Academy of Sciences,

Timiryazevska 1, 01014 Kyiv, Ukraine

\section{Alla Kuklina}

Main Botanical Garden Russian Academy of Sciences, Botanicheskaya 4, 127276 Moscow, Russia

\section{Jan Brindza}

Slovak University of Agriculture in Nitra, Institute of Biodiversity Conservation and Biosafety,

Trieda Andreja Hlinku 2, 94976 Nitra, Slovakia

Corresponding author: gbsad@mail.ru

Main Botanical Garden Russian Academy of Sciences, Botanicheskaya 4, 127276 Moscow, Russia

Useful wild plants usually decrease the content of biologically active substances in culture. However, there are no studies on the reverse process and no evidence whether the level of biologically active compounds increases in plants escaping from culture and becoming invaded in natural communities (invasive species). We studied Aronia melanocarpa, A. arbutifolia, A. x prunifolia, 2 samples of cultivated A. mitschurinii in the arboretum of the Main Botanical Garden (Moscow, Russia) and one sample of invasive A. mitschurinii from the Moscow region. The task of the study was to determine the degree of heritability of macro- and micromorphological characters of North American plants introduced to Europe. The identification of the samples most promising for further broad cultivation by their antioxidant activity and the content of microelements in leaves was also our 
research purpose. The diagnostic features of the introduced North American Aronia were found to be inherited under culture conditions. The mass of fruits increases in this order: $A$. arbutifolia $\rightarrow$ naturalised $A$. mitschurinii $\rightarrow$ A. $x$ prunifolia $\rightarrow$ A. melanocarpa $\rightarrow$ cultivated A. mitschurinii. An original table was compiled to compare the studied taxa on 21 biomorphological features. Naturalising plants have a higher antioxidant activity of alcohol extracts than cultivated plants, and, on the contrary, lower antioxidant activity of water extracts. The leaves of A. mitschurinii have the highest content of 10 microelements: $\mathrm{Fe}, \mathrm{Mn}, \mathrm{Sr}, \mathrm{Zn}, \mathrm{Se}, \mathrm{Cu}, \mathrm{Mo}, \mathrm{Cr}, \mathrm{As}$ and $\mathrm{Sb} ; \mathrm{A}$. $x$ prunifolia has the highest content of 6 microelements: $\mathrm{Ni}, \mathrm{Co}, \mathrm{V}, \mathrm{Cd}, \mathrm{Pb}$, and $\mathrm{Sn}$; and $\mathrm{A}$. arbutifolia has the highest content of B. Our observations suggest that naturalising plants of Aronia have a potential source of useful bioactive compounds.

Keywords: Aronia spp., fruit, antioxidant activity, microelement.

\section{Introduction}

It is known that wild useful plants, having got into the conditions of culture, often lose some part of their biologically active substances (Schippman et al., 2006). It is equally interesting to study the reverse process. After all, there is a whole group of species that, on the contrary, escape from culture and transform into invasive species. Do biomorphological and biochemical characters of invasive taxa differ from those of cultivated plants? Can the level of biologically active compounds increase in less favourable ecological conditions? The task of this study was to clarify this issue.

The search for new resource plant species has worried the humanity since time immemorial. However, so far only about $5 \%$ of plants are widely cultivated. Meanwhile, nowadays a whole group of plants - invasive species - has been formed; their secondary distribution range is expanding year by year, their resource reserves in the new homeland are very high, but the possibility of using them has not been studied (Vinogradova and Kuklina, 2012). In this respect, the genus Aronia Medik. attracts attention. Aronia mitschurinii (Skvortsov and Maitulina, 1982; Skvortsov et al., 1983) has already become invasive in Russia, and three others are highly resistant to culture, but have not yet found wide application, although, according to the latest data, they possess economically valuable traits (Kokotkiewicz et al., 2010).

The natural distribution range of Aronia is located in the eastern part of North America from Newfoundland and the southern part of the provinces Quebec and Ontario in the north to Florida peninsula in the south.

The genus Aronia consists of two species, which in early floras were included in the genus Mespilus L.
(Michaux, 1803) as subspecies: M. arbutifolia L. var. a erythrocarpa and M. arbutifolia L. var. $\beta$ melanocar$p a$. Later Elliott classified them as separate species into an independent genus Aronia (Elliott, 1821). In his treatment $A$. arbutifolia was subdivided into 2 subspecies: var. a-tomentosa and var. $\beta$-glabra. Elliott noted that he personally never saw mountain species $A$. melanocarpa, but in his opinion, it was no different from $A$. arbutifolia var. $\beta$-glabra (Table 1).

According to a later nomenclature (Rehder, 1949; Hardin, 1973), in North America, the genus Aronia consists of three species: A. melanocarpa, A. arbutifolia and their hybrid $A$. $\times$ prunifolia. At the same time, the authors indicate a significant variability of the taxa, especially $A$. arbutifolia (Table 1). All three species have been cultivated in European gardens since the beginning of the $19^{\text {th }}$ century.

At the end of the $19^{\text {th }}$ century, $A$. melanocarpa from Germany was brought to Tambov province (Russia) to the nursery of I. V. Michurin. There, by the method of 'screening in three generations', a man-made $A$. mitschurinii was born. It is still unclear whether this taxon arose as a result of macromutation, or it is a hybrid between A. melanocarpa and Sorbus spp. Undoubtedly, however, A. mitschurinii, both by morphological and by genetic characteristics, differs so much from the parental $A$. melanocarpa, which is quite correctly described as a special species.

At first, A. mitschurinii was grown as a fruit crop enriched in vitamins and minerals. In the 1960s, the discovery of a high content of P-vitamin substances in its berries led to the use of Aronia juice in medical 


\section{Table 1}

Taxonomic revisions of the genus Aronia Medik

\begin{tabular}{|c|c|c|}
\hline Michaux, 1803 & Elliott, 1821 & Rehder, 1949; Hardin, 1973 \\
\hline 1 & 2 & 3 \\
\hline $\begin{array}{l}\text { Mespilus arbutifolia L. var. a erythrocarpa } \\
\text { (lower leaf blade pubescent, fruits red) }\end{array}$ & $\begin{array}{l}\text { Aronia arbutifolia var. a - tomentosa (shoots up } \\
\text { 5-8 feet, calyx and lower leaf blade pubescent) }\end{array}$ & A. arbutifolia (L.) Elliott fruits red \\
\hline \multirow[t]{2}{*}{$\begin{array}{l}\text { Mespilus arbutifolia L. var. } \beta \text { melanocarpa } \\
\text { (lower leaf blade glabrous, fruits black) }\end{array}$} & $\begin{array}{l}\text { Aronia arbutifolia var. } \beta \text { - glabra (shoots up } \\
\text { 3-5 feet, calyx glabrous, young leaves slightly } \\
\text { pubescent, mature leaves glabrous). }\end{array}$ & $\begin{array}{l}\text { A. melanocarpa (Michx.) Elliott c } \\
\text { fruits black (= A. grandifolia Lindl.) }\end{array}$ \\
\hline & & $\begin{array}{l}\text { A. } \times \text { prunifolia (Marsh.) Rehd. } \\
(=\text { A. } \times \text { floribunda Spach. }(=A . \\
\text { arbutifolia } \times \text { A. melanocarpa })\end{array}$ \\
\hline
\end{tabular}

institutions for the treatment of hypertension. Now this species has been tested as a source of antioxidant activity due to the high content of polyphenols (Mayer-Miebach et al., 2012; Bräunlich, 2013; Taheri, 2013), namely cyanidin anthocyanins, proanthocyanins, flavonols, chlorogenic acid and neochlorogenic acid (Oszmiański and Wojdylo, 2005; Slimestad et al., 2005; Koponen et al., 2007). The juice from fruits of Aronia has an antimutagenic activity (Gasiorowski et al., 1997), a gastroprotective effect (Matsumoto et al., 2004), hepatoprotective activity (Valcheva-Kuzmanova and Belcheva, 2006), anticancer activity (Sharif et al., 2012), cardioprotective and antidiabetes effects (Kulling and Rawel, 2008; Denev et al., 2012), an anti-inflammatory effect (Martin et al., 2014), and antiatherogenic activity (Daskalova et al., 2015).

In the 1990s, cultural Aronia returned to the homeland of its ancestors - North America. The circle is finished. Now, in the US, both species are grown: the parent $A$. melanocarpa for reintroduction into natural cenoses and the 'daughter' A. mitschurinii for the production of food colouring used in the confectionery and wine industry.

The University of Wisconsin-Madison Center for Integrated Systems evaluated 13 potential uncommon fruits with sustainability potential. Aronia was chosen as the crop with the greatest potential, beating out currants, gooseberries, and elderberries. Low input requirements, high adaptability, high pest resistance, high nutraceutical content, short time to the first yield, ease of culture, and high machine harvest potential were given as the reasons why Aronia is tops for commercial production potential (Brand, 2010).
According to the Global New Product Database, the fruits of Aronia, thanks to the high content of phenolic compounds, have recently been considered as the most promising product of healthy food (GNPD, 2018). About 100 years $A$. mitschurinii was cultivated on the plantations and household plots throughout Russia. Quite unexpectedly, it became wild, began to run away from culture and invaded natural communities - marshes and forests with a mossy synfolium (Vinogradova and Kuklina, 2014). How much the genotype of naturalsed plants and their biochemical characters changed was unknown until nowadays.

The task of the study was to determine the degree of heritability of macro- and micromorphological characters of North American plants introduced to Europe and their comparison with the analogous parameters of $A$. mitschurinii. The identification of the samples most promising for further broad cultivation by their antioxidant activity and the content of microelements in leaves was also part of the research purpose.

\section{Materials and methods}

\section{Biological material}

We studied A. melanocarpa, A. arbutifolia and A. $\times$ prunifolia in the arboretum of the Main Botanical Garden of the Russian Academy of Sciences (Moscow, Russia). The plants were brought from the USA in the 1980s. Two samples of cultivated A. mitschurinii from the Chekhov and Dmitrov districts of the Moscow 
region and one sample of naturalised $A$. mitschurinii from the Orekhovo-Zuevsky district of the Moscow region were also included in the analysis.

\section{Macromorphological characteristics}

The most significant characteristics for cultivation were determined in details: the size and weight of the fruit. Fruits were collected from at least three individuals. Each specimen consisted of 25 fruits.

\section{Micromorphological characteristics}

Keyence VHX 1000E digital microscope and scanning electron microscope LEO 1430 VP were used to examine leaves by the trichome density and stoma's parameters. The measurements were performed using the AxioVision software package. The measurement of the gland's length on the upper side of the leaf blade was performed on a sample of 30 glands in triplicate. The size of the stomata was determined on varnish replicas from the leaves of the middle formation from flowering plants. The sample consisted of 50 stomata. The number of stomata was counted in the microscope field of view $300 \times 250 \mu \mathrm{m}$ in triplicate.

\section{Antioxidant analysis}

\section{Chemicals}

All the chemicals used were of the analytical grade and were purchased from Sigma-Aldrich (St. Louis, MO, USA) and CentralChem (Slovakia).

\section{Elemental composition of leaves}

Aronia leaves were dried for $48 \mathrm{~h}$ at $25-30^{\circ} \mathrm{C}$ and stored in a dry and dark place at the ambient temperature. All plant samples were digested using a closed microwave assisted system. For the sample preparation, an MWS-2 Microwave System Speedwave from Berghof Laborprodukte $\mathrm{GmbH}$ (Eningen, Germany) was used. Each sample was digested in duplicate, whereby about $0.5 \mathrm{~g}$ (weighed to the nearest $0.1 \mathrm{mg}$ ) was put into a Teflon reaction vessel, and $5 \mathrm{~mL}$ of HNO3 (50:50 v/v) were added. The digestion procedure was carried out according to the following programme consisting of three steps of 15 min each: $110^{\circ} \mathrm{C}, 170^{\circ} \mathrm{C}, 140^{\circ} \mathrm{C}$. Blank solutions were prepared in the same way. The clear solutions were obtained and then brought to final $10.0 \mathrm{~mL}$ with ultrapure water.

The elemental concentrations in the clear solutions were measured in triplicate by inductively coupled plasma atomic absorption spectrometry (ICP-MS) by ICP-MS spectrometer Agilent 7700x from Agilent Technologies (USA).

Free radical scavenging activity

Free radical scavenging activity was measured by 2.2-diphenyl-1-picrylhydrazyl (DPPH.) method according to Brand-Williams et al. (1995). This test is based on the reaction of radical discolouration (colour of the radical solution is purple). The procedure of determination of optical density was measured with a spectrophotometer (Genesys 20 UV-VIS, USA) at wavelength $515 \mathrm{~nm}$. Plant raw material was dried at the room temperature and powdered. Dry mass $(1 \mathrm{~g})$ of investigated plants was mixed with $25 \mathrm{~mL}$ of solvent. Extraction was carried out with methanol, ethanol and water during 12 hours with constant stirring on a shaker. The obtained extracts were filtrated (Whatman No. 1) and $0.1 \mathrm{~mL}$ of antioxidant solution was added to $3.9 \mathrm{~mL}$ of methanol $\mathrm{DPPH}$. solution ( $25 \mathrm{mg}$ of radical per $100 \mathrm{~mL}$ of methanol with further dilution). The optical density of the solution was measured after adding the sample immediately and after $10 \mathrm{~min}$ of incubation in the dark. The obtained results were calculated in percentage by using the following equation:

$$
\% \operatorname{Inh}=\frac{A_{o}-A_{1}}{A_{o}} \times 100
$$

Where: $A_{0}$ - absorbance of control reaction; $A_{1}$ - absorbance in presence of the sample.

\section{Statistical analysis}

Basic statistical analyses were performed using PAST 2.17. Hierarchical cluster analyses of similarity between the taxa were computed on the basis of the Bray-Curtis similarity index. Multi-dimensional scaling (MDS) analyses were performed in PRIMER (Clarke and Gorley 2006). Data were analysed with ANOVA test and the differences between the means were compared by the Tukey-Kramer test $(a=0.05)$.

\section{Results and Discussions}

\section{Macromorphological characteristics}

The attention is drawn, first of all, to the difference in the fruit size and weight of the various Aronia taxa. The air-dry mass of one berry was greatest in 
cultivated Aronia mitschurinii (an average of $197 \mathrm{mg}$ ), and the smallest (in 4 times) was in A. arbutifolia (an average of $44 \mathrm{mg}$ ). The mass of fruits increases in the series $A$. arbutifolia $\rightarrow$ naturalised $A$. mitschurinii $\rightarrow$ A. $\times$ prunifolia $\rightarrow$ A. melanocarpa $\rightarrow$ cultivated A. mitschurinii, Chekhov $\rightarrow$ cultivated $A$. mitschurinii, Dmitrov (Fig. 1). The fruit weight of $A$. mitschurinii, cultivated in the Moscow region, was of a more stable character than the fruit weight of plants cultivated in Ukraine (Vinogradova et al., 2017).

A comparative analysis of other macromorphological characteristics of Aronia taxa is given in Table 2. All diagnostic features in cultivated plants persist. A. melanocarpa shoots are glabrous, the leaves are from elliptical to oval-lanceolate, $2-6 \mathrm{~cm}$ long, and
Fig. 1

The air-dry fruit weight (mg) for different Aronia taxa: 1 - A. arbutifolia; 2 - naturalised $A$. mitschurinii; 3 - A. x prunifolia; 4-A. melanocarpa; 5 cultivated A. mitschurinii, Chekhov; 6 - cultivated A. mitschurinii, Dmitrov

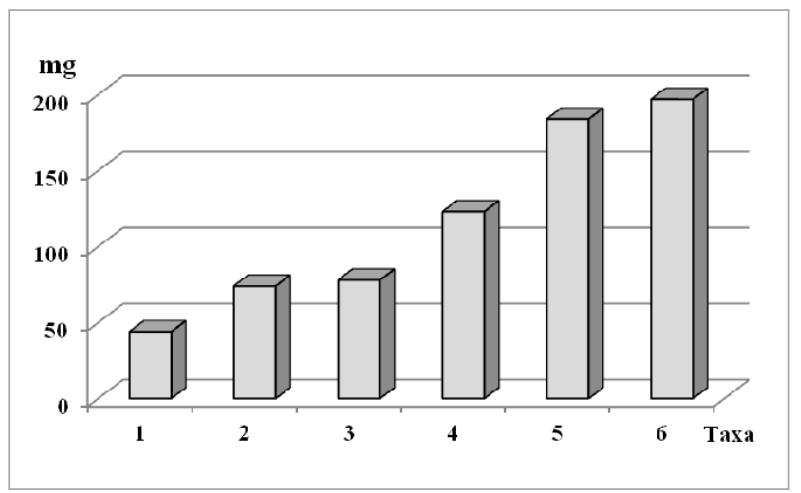

Table 2

The ranking of bio-morphological characteristics for Aronia taxa

\begin{tabular}{|c|c|c|c|c|}
\hline Characteristic & $\begin{array}{c}\text { Aronia } \\
\text { arbutifolia }\end{array}$ & $\begin{array}{c}\text { Aronia } \\
\text { prunifolia }\end{array}$ & $\begin{array}{c}\text { Aronia } \\
\text { melanocarpa }\end{array}$ & $\begin{array}{c}\text { Aronia } \\
\text { mitschurinii }\end{array}$ \\
\hline 1 & 2 & 3 & 4 & 5 \\
\hline Maximum height of the bush: $1-<2 \mathrm{~m} ; 2-2-4 \mathrm{~m}$ & 2 & 2 & 1 & 2 \\
\hline Shape of bush: 1 - upright; 2 - semisprawling & 2 & 1 & 2 & 2 \\
\hline Annual shoots: 0 - glabrous; 1 - slightly pubescent & 0 & 1 & 0 & 0 \\
\hline The length of the leaf blade: $1-<4 \mathrm{~cm} ; 2-4-6 \mathrm{~cm} ; 3->6 \mathrm{~cm}$ & 1 & 3 & 2 & 2 \\
\hline The length/weight of the leaf blade: $1-<1.5 ; 2-1.5-2.0 ; 3->2$ & 1 & 3 & 2 & 2 \\
\hline The top of the leaf blade: 1 - with tip; 2 - rounded & 2 & 2 & 1 & 1 \\
\hline Base of the leaf blade: 1 - cuneate; 2 - wide-cuneate & 3 & 2 & 2 & 3 \\
\hline The underside of the leaf blade: 1 - slightly pubescent; 2 - strongly pubescent & 2 & 2 & 1 & 1 \\
\hline Average length of stoma: $1-24-33 \mu \mathrm{m} 2->33 \mu \mathrm{m}$ & 1 & 1 & 1 & 2 \\
\hline Average diameter of stoma: $1-19-22 \mu \mathrm{m} ; 2->22 \mu \mathrm{m}$ & 2 & 2 & 2 & 3 \\
\hline Inflorescence axes: 0 - glabrous; 1 - pubescent & 1 & 1 & 0 & 1 \\
\hline The average number of flowers in the inflorescence: $1-<10 ; 2-10-20 ; 3->20$ & 1 & 1 & 2 & 3 \\
\hline Fruit colour: 1 - red; 2 - dark red; 3 - black & 1 & 2 & 3 & 3 \\
\hline Fruit surface: 1 - bright; 2 - matt & 2 & 1 & 1 & 2 \\
\hline Diameter of fruit: $1-<9 \mathrm{~mm} ; 2->9 \mathrm{~mm}$ & 1 & 1 & 1 & 2 \\
\hline Fruit shape: 1 - pear-shaped; 2 - spherical & 1 & 1 & 1 & 2 \\
\hline Fruit taste: 0 - inedible; 1 - edible & 0 & 0 & 0 & 1 \\
\hline Chromosome number: 1 - diploid $(2 n=34) ; 2$ - tetraploid $(2 n=68)$ & 1 & 1 & 1 & 2 \\
\hline Reproduction: 1 - amphimictic; 2 - apomictic & 1 & 1 & 1 & 2 \\
\hline $\begin{array}{l}\text { Cold resistance: } 1 \text { - moderate (IV zone, Rehder, 1949); } 2 \text { - high (zone II, } \\
\text { Rehder, 1949) }\end{array}$ & 1 & 1 & 1 & 2 \\
\hline $\begin{array}{l}1 \text { - morphological characters are greatly variable; } 2 \text { - highly homogenous } \\
\text { gene pool }\end{array}$ & 1 & 1 & 1 & 2 \\
\hline
\end{tabular}


the fruits are black. In A. arbutifolia, shoots are pubescent, leaves are from elliptical to oblong or obovate, $3-4 \mathrm{~cm}$ in length, the apex is sharp, lobes of calyx with glands, fruits are dull reddish, 5-7 $\mathrm{mm}$ in diameter, pear-shaped, and do not fall off for a long time. Hybridogenic A. $\times$ prunifolia (Marshall) Rehder (= A. arbutifolia $\times$ A. melanocarpa). $=$ A. floribunda Spach., A.atropurpurea Britt., Sorbus arbutifolia var. atropurpurea Schneid. has inflorescence loss, calyx less pubescent with lobes without glands, fruits purplish black, 8-10 $\mathrm{mm}$ in diameter, shiny. Leaf pubescence varies from medium to plentiful (Brand, 2010), and most morphological features (fruit colouring, fruit ripening time, plant habit) have also an intermediate character.

All parameters of morphological features in plants under culture conditions do not exceed the norm of reaction for the analogous genotypes in the natural distribution range.

\section{Micromorphological characteristics}

The underside of the leaf blade of $A$. melanocarpa is covered with long tangled hairs, and especially numerous trichomes are on the main vein. The upper side of the leaf blade is glossy, there are practically no trichomes on it, but reddish glands (up to $4 \mathrm{pcs} / \mathrm{mm}$ ) are located along the main vein, and their length is $390-$ $704(577 \pm 52) \mu \mathrm{m}$. All the characteristics of $A$. mitshurinii leaves are identical to those of $A$. melanocarpa.

Leaves of $A$. arbutifolia in the lower third of the edge have cilia. The underside of the leaf blade is abundantly covered with long tangled trichomes (more densely than for A. melanocarpa). The lots of trichomes are on the main vein. The upper side of the leaf blade is glossy, there are practically no trichomes on it, but on the main vein there are numerous reddish glands (up to $13 \mathrm{pcs} /$ $\mathrm{mm})$, its length is $218-559(284 \pm 32) \mu \mathrm{m}$. They are more abundant but shorter than for $A$. melanocarpa.

In A. $x$ prunifolia, the underside of the leaf blade is abundantly pubescent, not only over veins, but also over the entire surface. The upper side of the leaf blade is glossy, there are no trichomes on it, and reddish glands are located along the main vein. The gland number is similar to $A$. melanocarpa (up to $4 \mathrm{pcs} / \mathrm{mm}$ ), its average length is similar to that of $A$. arbutifolia $(371 \pm 28$ $\mu \mathrm{m})$, and the amplitude of variability is $293-540 \mu \mathrm{m}$.

The leaves are hypostomatic for all species: the stomata are located only on the lower side of the leaf blade and abaxial stomata are not presented. Alone abaxial stoma was found only in $A$. $x$ prunifolia. The adaxial stomata have different sizes - from small to large. Leaves of $A$. melanocarpa have 9-10 stomata (an average size of $35 \times 23 \mu \mathrm{m}$ ) in the ocular view. Leaves of $A$. arbutifolia have 10-11 stomata with a size of $32 \times 22 \mu \mathrm{m}$, and leaves of $A$. $\times$ prunifolia have 6-7 stomata with a size of $32 \times 20 \mu \mathrm{m}$ (Fig. 2).

\section{Fig. 2}

Stomata size of Aronia taxa: $\mathrm{A}$ - the length of stoma; $\mathrm{B}$ - the diameter of stoma; red $-A$. arbutifolia; blue $-A$. melanocarpa; violet $-A$. prunifolia

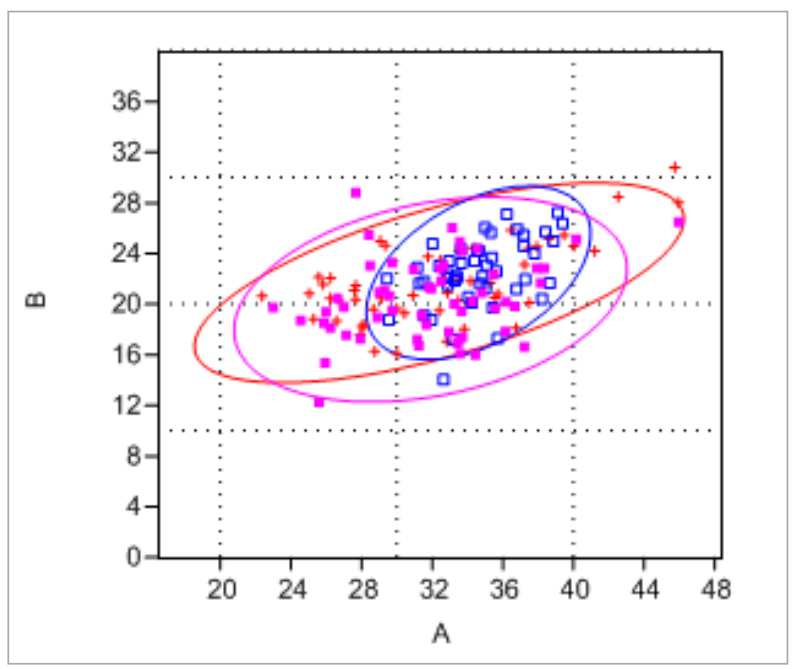

Fig. 3

Cluster dendrogram of studied Aronia taxa on their biomorphological characters: 1 - A. arbutifolia; 2 - A. prunifolia; 3 - A. melanocarpa; $4-A$. mitschurinii

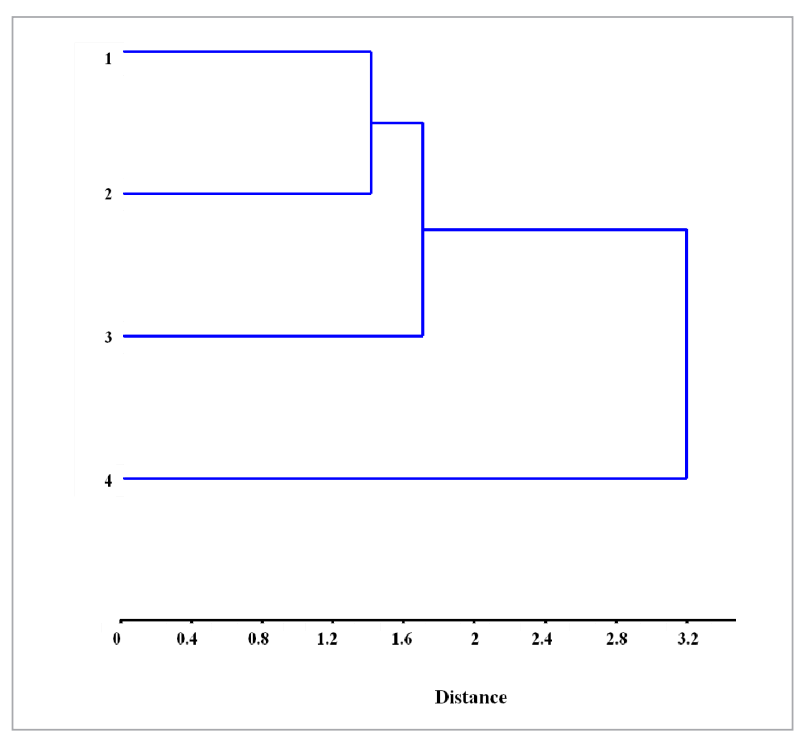


Based on the cluster analysis of all studied characteristics (Table 2), a dendrogram for all taxa of Aronia was made (Fig. 3). On the dendrogram, A. mitschurinii is really separated from the other North American taxa. A. prunifolia occupies an intermediate position between two parental species - A. arbutifolia and $A$. melanocarpa.

\section{Elemental analysis of leaves}

Elemental composition of Aronia leaves is listed in Table 3 as mean values. Among the major elements, the most abundant are Fe and $\mathrm{B}$, followed by $\mathrm{Mn}$ and $\mathrm{Zn}$. Sr, $\mathrm{Cu}, \mathrm{Se}$ and $\mathrm{Ni}$ are the most abundant among the microelements. In terms of heavy metals (As, Cd, $\mathrm{Pb}$ ), it can be concluded that their concentrations are below permissible levels prescribed by national legislation in all samples.

Since soil composition, ripeness state, climate and environmental conditions and genetic background influence the accumulation of elements, these obtained differences are to be expected. Leaves of cultivated $A$. mitschurinii have the highest content (among the studied Aronia taxa) of 10 out of $17 \mathrm{mi}-$ croelements: $\mathrm{Fe}, \mathrm{Mn}, \mathrm{Sr}, \mathrm{Zn}, \mathrm{Se}, \mathrm{Cu}, \mathrm{Mo}, \mathrm{Cr}$, As and Sb, with berries having 4 elements ( $\mathrm{Mn}, \mathrm{Sr}, \mathrm{Zn}$, and $\mathrm{As}$ ). Leaves of $A$. $\times$ prunifolia have the highest content of 6 elements: $\mathrm{Ni}, \mathrm{Co}, \mathrm{V}, \mathrm{Cd}, \mathrm{Pb}, \mathrm{Sn}$, while berries have 8 elements ( $\mathrm{Se}, \mathrm{Cu}, \mathrm{Ni}, \mathrm{Sn}, \mathrm{Cr}, \mathrm{V}, \mathrm{Cd}$ and $\mathrm{Pb}$ ); and leaves of $A$. arbutifolia have the highest content of $\mathrm{B}$, while berries have 5 elements ( $\mathrm{Fe}, \mathrm{B}, \mathrm{Sb}, \mathrm{V}$ and $\mathrm{Pb}$ ).

Comparing Aronia berries and leaves with the fruits from Sorbus domestica (Zeiner et al., 2017), it can be seen that selenium ( $\mathrm{Se}$ ) is present in big amounts in all samples. Selenium (Se) is an essential trace element for animals and humans because of its role in an antioxidant enzyme glutathione peroxidase. This enzyme protects cell membranes from damage caused by the peroxidation of lipids. The major source

\section{Table 3}

The content of microelements (ppm) in the leaves and berries of Aronia taxa (values are the mean \pm standard deviation (SD), $\mathrm{n}=3 ; \mathrm{mean}$ values with different Aronia taxa are significantly different; $p<0.05$ )

\begin{tabular}{c|c|c|c|c|c|c}
\hline \multirow{2}{*}{ Microelements } & \multicolumn{5}{|c|}{ Leaves } & \multicolumn{3}{c}{ Berries } \\
\cline { 2 - 7 } & $\begin{array}{c}\text { Aronia } \\
\text { mitschurinii }\end{array}$ & $\begin{array}{c}\text { Aronia } \times \\
\text { prunifolia }\end{array}$ & $\begin{array}{c}\text { Aronia } \\
\text { arbutifolia }\end{array}$ & $\begin{array}{c}\text { Aronia } \\
\text { mitschurinii }\end{array}$ & $\begin{array}{c}\text { Aronia } \times \\
\text { prunifolia }\end{array}$ & $\begin{array}{c}\text { Aronia } \\
\text { arbutifolia }\end{array}$ \\
\hline $\mathrm{Fe}$ & $124.16 \pm 5.94$ & $105.90 \pm 2.05$ & $109.18 \pm 3.67$ & $76.34 \pm 1.30$ & $68.04 \pm 1.04$ & $77.84 \pm 2.64$ \\
\hline $\mathrm{B}$ & $61.86 \pm 1.43$ & $47.31 \pm 2.54$ & $62.6 \pm 1.40$ & $20.89 \pm 1.26$ & $24.87 \pm 0.89$ & $29.07 \pm 1.08$ \\
\hline $\mathrm{Mn}$ & $39.20 \pm 1.18$ & $23.42 \pm 1.32$ & $27.48 \pm 0.97$ & $13.83 \pm 0.39$ & $7.08 \pm 0.63$ & $9.91 \pm 0.72$ \\
\hline $\mathrm{Sr}$ & $24.02 \pm 0.74$ & $10.21 \pm 0.23$ & $9.95 \pm 1.01$ & $9.88 \pm 0.47$ & $7.76 \pm 0.17$ & $7.06 \pm 0.28$ \\
\hline $\mathrm{Zn}$ & $12.24 \pm 0.63$ & $9.62 \pm 0.54$ & $7.58 \pm 0.62$ & $6.30 \pm 0.60$ & $4.27 \pm 0.49$ & $3.81 \pm 0.35$ \\
\hline $\mathrm{Se}$ & $7.72 \pm 0.25$ & $6.50 \pm 0.63$ & $5.32 \pm 0.15$ & $6.74 \pm 0.21$ & $6.97 \pm 0.25$ & $6.53 \pm 0.37$ \\
\hline $\mathrm{Cu}$ & $4.37 \pm 1.06$ & $2.83 \pm 0.21$ & $2.05 \pm 0.39$ & $2.49 \pm 0.17$ & $2.77 \pm 0.32$ & $1.89 \pm 0.18$ \\
\hline $\mathrm{Ni}$ & $0.54 \pm 0.10$ & $2.90 \pm 0.41$ & $2.80 \pm 0.17$ & $0.09 \pm 0.02$ & $0.33 \pm 0.09$ & $0.21 \pm 0.05$ \\
\hline $\mathrm{Co}$ & $0.03 \pm 0.005$ & $0.22 \pm 0.068$ & $0.11 \pm 0.015$ & $0.01 \pm 0.003$ & $0.06 \pm 0.005$ & $0.02 \pm 0.005$ \\
\hline $\mathrm{Sn}$ & $0.22 \pm 0.011$ & $0.29 \pm 0.020$ & $0.17 \pm 0.019$ & $0.09 \pm 0.008$ & $0.16 \pm 0.020$ & $0.09 \pm 0.004$ \\
\hline $\mathrm{V}$ & $0.12 \pm 0.016$ & $0.19 \pm 0.014$ & $0.12 \pm 0.012$ & $0.07 \pm 0.004$ & $0.08 \pm 0.002$ & $0.08 \pm 0.001$ \\
\hline $\mathrm{Mo}$ & $0.24 \pm 0.026$ & $0.07 \pm 0.003$ & $0.07 \pm 0.007$ & $0.10 \pm 0.011$ & $0.06 \pm 0.009$ & $0.09 \pm 0.005$ \\
\hline $\mathrm{Cr}$ & $0.09 \pm 0.002$ & $0.07 \pm 0.001$ & $0.07 \pm 0.002$ & $0.08 \pm 0.009$ & $0.11 \pm 0.016$ & $0.07 \pm 0.008$ \\
\hline $\mathrm{Sb}$ & $0.22 \pm 0.005$ & $0.29 \pm 0.019$ & $0.17 \pm 0.011$ & $0.08 \pm 0.004$ & $0.09 \pm 0.005$ & $0.10 \pm 0.013$ \\
\hline $\mathrm{As}$ & $0.08 \pm 0.005$ & $0.02 \pm 0.004$ & $0.07 \pm 0.008$ & $0.08 \pm 0.003$ & $0.03 \pm 0.006$ & $0.04 \pm 0.002$ \\
\hline $\mathrm{Cd}$ & $0.07 \pm 0.008$ & $0.31 \pm 0.037$ & $0.26 \pm 0.013$ & $0.02 \pm 0.006$ & $0.09 \pm 0.003$ & $0.09 \pm 0.005$ \\
\hline $\mathrm{Pb}$ & $0.11 \pm 0.009$ & $0.23 \pm 0.026$ & $0.06 \pm 0.009$ & $0.01 \pm 0.004$ & $0.08 \pm 0.007$ & $0.02 \pm 0.003$ \\
\hline
\end{tabular}


of Se is plants, and in many regions of the world, the levels of Se in the soils generally reflect the Se status in plant populations. In plant products, bioavailability and toxicity of Se depend on its chemical forms. Organic forms of Se are more bioavailable and less toxic than the inorganic forms (selenites, selenates).

Moreover, the data obtained in this study showed that naturalising plants of Aronia are potentially a rich source of some dietary metals such are Fe, Mn, Zn and $\mathrm{Cu}$. Iron is an important component of the cytochromes that function in cellular respiration. Red blood cells cannot function properly without iron in haemoglobin, the oxygen-carrying pigment of red blood cells. Copper (Cu), zinc (Zn), iron (Fe) and manganese $(\mathrm{Mn})$ are important co-factors found in the structure of certain enzymes and are indispensable in numerous biochemical pathways.

In addition to the known beneficial impact from Aronia leaves organic compounds, the mineral composition justifies its usage as a nutritional supplement. The toxic elements present do not pose any health risk when infusions from leaves are consumed. Obtained results could also be used as selection criteria for further use of products of Aronia as part of the conventional diet.

\section{Antioxidant activity}

The total antioxidant activity of extracts for all specimens was very high (Fig. 4) and had $83.25-93.30 \%$ of methanol extracts, $78.07-93.23 \%$ of ethanol extracts and $59.87-88.36 \%$ of aqueous extracts. Alcoholic and aquatic extracts of fruits had almost equal antioxidant activity. The lowest antioxidant activity in alcohol extracts was shown by cultivated $A$. mitschurinii, and the highest one was shown by invasive plants of $A$. mitschurinii. Conversely, aqueous extracts had the lowest antioxidant activity in invasive plants of $A$. mitschurinii and the highest one in cultivated samples.

Antioxidant activity of Aronia taxa is similar to that of wild-growing Sambucus nigra L.: a water extract from elderberry inflorescence was between $85.12 \%$ and $89.29 \%$; in an alcoholic extract from fresh inflorescences, anti-radical activity was between $90.99 \%$ and $93.16 \%$ (Horčinová Sedláčková et al., 2018). This index is similar also to that of Diospyros virginiana, which has been used in folk medicine of North American Indians because of its high antioxidant activity (Grygorieva et al., 2018).

\section{Fig. 4}

The total antioxidant activity of Aronia taxa: 1 - A. arbutifolia; 2 - Aronia mitschurinii (invasive); 3 - A. prunifolia; $4-A$. melanocarpa; 5 - A. mitschurinii (in culture, Tchehov); 5 - A. mitschurinii (in culture, Dmitrov). Means in columns followed by different letters are different at $p=0.05$. Each value represents the mean of three independent experiments $( \pm S D)$

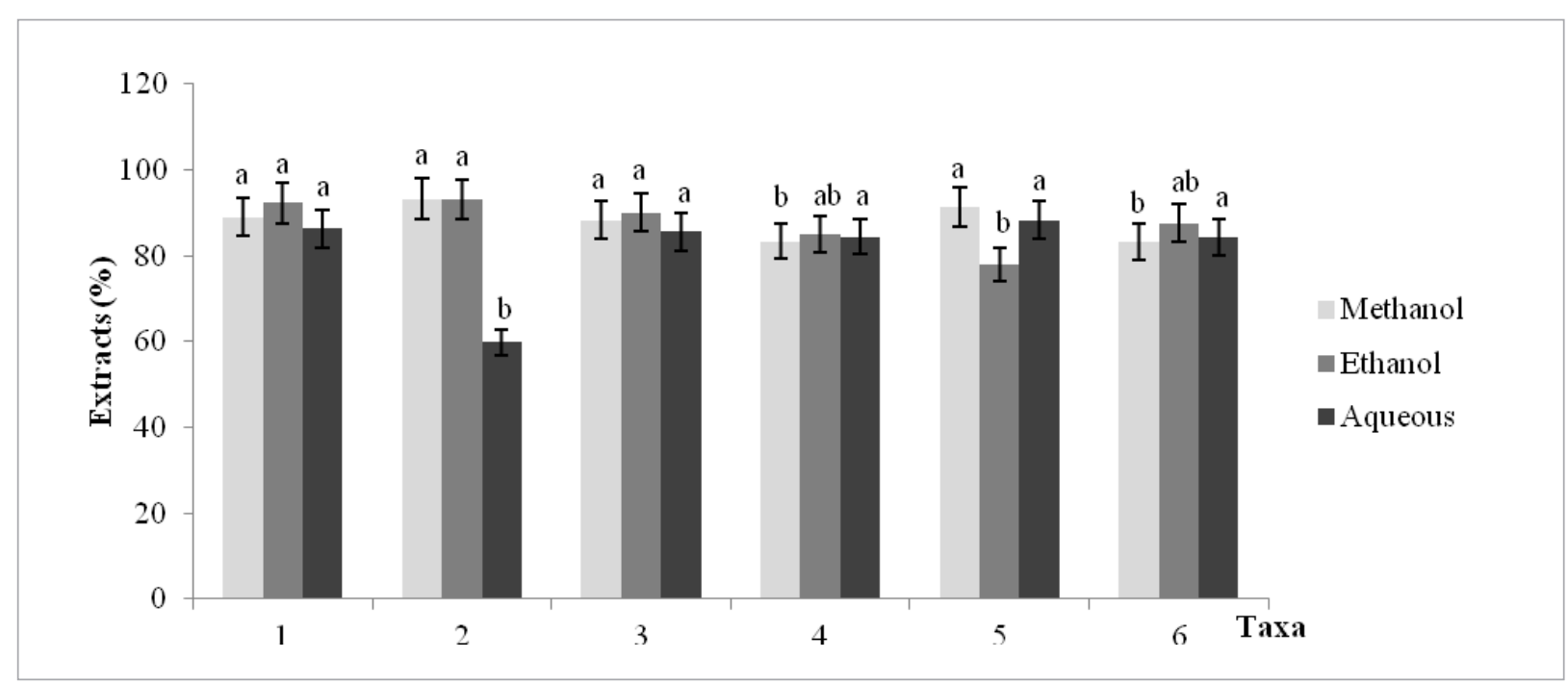




\section{Conclusions}

The diagnostic features of the introduced North American Aronia were found to be inherited under culture conditions. The mass of fruits increases in this order: $A$. arbutifolia $\rightarrow$ naturalised $A$. mitschurinii $\rightarrow$ A. $\times$ prunifolia $\rightarrow$ A. melanocarpa $\rightarrow$ cultivated $A$. mitschurinii.

A. mitschurinii has the highest content (among the studied Aronia taxa) of 10 out of 17 microelements: Fe, $\mathrm{Mn}, \mathrm{Sr}, \mathrm{Zn}, \mathrm{Se}, \mathrm{Cu}, \mathrm{Mo}, \mathrm{Cr}$, As and Sb; A. x prunifolia has the highest content of 6 microelements: $\mathrm{Ni}, \mathrm{Co}, \mathrm{V}, \mathrm{Cd}$, $\mathrm{Pb}, \mathrm{Sn}$; and $\mathrm{A}$. arbutifolia has the highest content of $\mathrm{B}$.

The total antioxidant activity in dry fruits was from 83\% (A. melanocarpa and cultivated A. mitschurinii) to $93 \%$ (naturalised $A$. mitschurinii) for methanol extracts, from 78\% (cultivated A. mitschurinii) to 93\% (naturalised A. mitschurinii) for ethanol extracts, and from $60 \%$ (naturalised $A$. mitschurinii) to $88 \%$ (cultivated $A$. mitschurinii) for water extracts. Thus, naturalising plants have a higher antioxidant activity of

alcohol extracts than cultivated plants, and, on the contrary, the lower antioxidant activity of water extracts.

Our observations suggest that naturalising plants of Aronia have a potential source of useful bioactive compounds. Apparently, plants in a comfortable culture environment accumulate fewer biologically active substances than during forced adaptation to unfavourable ecological conditions.

\section{Acknowledgements}

The publication was prepared with the active participation of researchers in international network AGROBIONET, as a part of international programme 'Agricultural biodiversity to improve nutrition, health and quality of life' within the project ITMS 25110320104 Innovation of test methods and procedures for the detection of sources of bioactive substances for the improvement of health and quality of life. The work was carried out in accordance with the MBG RAS Research Project No. 118021490111-5.

\section{References}

Brand M. (2010). Aronia: Native Shrubs with Untapped Potential. Arnoldia 67(3): 14-25.

Brand-Williams W., Cuvelier M.E., Berset C. (1995). Use of a free radical method to evaluate antioxidant activity. Lebenson Wiss Technol 28: 25-30. https://doi.org/10.1016/S00236438(95)80008-5

Bräunlich M. (2013). Bioactive constituents in Aronia berries : dissertation theses. University of Oslo. $110 \mathrm{p}$.

Clarke K., Gorley R. (2006). PRIMER v6: User Manual/Tutorial. Plymouth, UK : Primer-E, Ltd. $192 \mathrm{p}$.

Daskalova E., Delchev S., Peeva Yu., Vladimirova-Kitova L., Kratchanova M., Kratchanov Ch., Denev P. (2015). Antiatherogenic and Cardioprotective Effects of Black Chokeberry (Aronia melanocarpa) Juice in Aging Rats. Evidence-Based Complementary and Alternative Medicine 2015: 1-10. https://doi.org/10.1155/2015/717439

Denev P.N., Kratchanov C.G., Ciz M., Lojek A., Kratchanova M.G. (2012). Bioavailability and antioxidant activity of black chokeberry (Aronia melanocarpa) polyphenols: In vitro and in vivo evidences and possible mechanisms of action. A review Comprehensive Reviews in Food Science and Food Safety 11(5): 471-489. https://doi.org/10.1111/j.1541-4337.2012.00198.x

Elliott S. (1821). A Sketch of the Botany of South Carolina and Georgia. Missouri Botanical Garden. 606 p. https://doi. org/10.5962/bhl.title.9508

Gasiorowski K., Szyba K., Brokos B., Kołaczyńska B., Jankowiak-Włodarczyk M., Oszmiański J. (1997). Antimutagenic activity of anthocyanins isolated from Aronia melanocarpa fruits. Cancer Letters119(1): 37-46. https://doi.org/10.1016/S03043835(97)00248-6

Global New Product Database (2011). Available at: http://www. gnpd.com. (accessed 30 May 2018).

Grygorieva O., Kucharska A.Z., Piórecki N., Klymenko S., Vergun 0., Brindza J. (2018). Antioxidant activities and phenolic compounds in fruits of various genotypes of American persimmon (Diospyros virginiana L.). Acta Scientiarum Polonorum Technologia Alimentaria 17(2): 117-124. https://doi.org/10.17306/J. AFS.2018.0544

Hardin J.W. (1973). The enigmatic chockeberries. Bulletin Torrey Botanical Club 100(3): 178-184. https://doi. org/10.2307/2484630

Horčinová Sedláčková V., Grygorieva O., Fatrcová-Šramková K., Vergun O., Vinogradova Yu., Ivanišová E., Brindza J. (2018). The 
morphological and antioxidant characteristics of inflorescences within wild-growing genotypes of elderberry (Sambucus nigra L.). Potravinarstvo Slovak Journal of Food Sciences 12(1): 444453. https://doi.org/10.5219/919

Kokotkiewicz A., Jaremicz Z., Luczkiewicz M. (2010). Aronia Plants: A Review of Traditional Use, Biological Activities, and Perspectives for Modern Medicine. Journal of Medicinal Food 13(2): 255-269. https://doi.org/10.1089/jmf.2009.0062

Koponen J.M., Happonen A.M., Mattila P.H., Torronen A.R. (2007). Contents of anthocyanins and ellagitannins in selected foods consumed in Finland. Journal of Agricultural and Food Chemistry 55(4): 1612-1619. https://doi.org/10.1021/jf062897a

Kulling S.E., Rawel H.M. (2008). Chokeberry (Aronia melanocarpa) - A review on the characteristic components and potential health effects. Planta Medica 74(2008): 1625-1634. https://doi. org/10.1055/s-0028-1088306

Martin D.A., Taheria R., Brand M.H., Draghi A., Sylvester F.A., Bollinga B.W. (2014). Anti-inflammatory activity of Aronia berry extracts in murine splenocytes. Journal of Functional Foods 8: 68-75. https://doi.org/10.1016/j.jff.2014.03.004

Matsumoto M., Hara H., Chiji H., Kasai T. (2004). Gastroprotective effect of red pigments in black chokeberry fruit (Aronia melanocarpa Elliot) on acute gastric hemorrhagic lesions in rats. Journal of Agricultural and Food Chemistry 52(8): 2226-2229. https://doi.org/10.1021/jf034818q

Mayer-Miebach E., Adamiuk M., Behsnilian D. (2012). Stability of Chokeberry Bioactive Polyphenols during Juice Processing and Stabilization of a Polyphenol-Rich Material from the By-Product. Agriculture 2(3): 244-258. https://doi.org/10.3390/agriculture2030244

Michaux A. (1803). Flora Boreali-Americana. Typis Caroli Crapelet, Parisiis et Argentorati, Apud fraters Levrault 1. 330 p.

Oszmiański J., Wojdylo A. (2005). Aronia melanocarpa phenolics and their antioxidant activity. European Food Research and Technology 221(6): 809-813. https://doi.org/10.1007/s00217-005-0002-5

Rehder A. (1949). Manual of cultivated trees and shrubs. N.-Y: MacMillan Company. 996 p.
Schippmann U., Leaman D., Cunningham A.B. (2006). A comparison of cultivation and wild collection of medicinal and aromatic plants under sustainability aspects. In: Lange D. ed.Medicinal and Aromatic Plants. Springer.Printed in the Netherlands: 75-95. https://doi.org/10.1007/1-4020-5449-1_6

Sharif T., Alhosin M., Auger C., Minker C., Kim J.H., Etienne-Selloum N., Bories P., Gronemeyer H., Lobstein A., Bronner C., Fuhrmann G., Schini-Kerth V.B. (2012). Aronia melanocarpa juice induces a redox-sensitive p73-related caspase 3-dependent apoptosis in human leukemia cells. PLoS One 7(3): e32526. https://doi.org/10.1371/journal.pone.0032526

Skvortsov A.K., Maitulina Yu.K. (1982). On distinctions of cultivated black-fruited aronia from its wild ancestors. Available at : http://www.salicicola.com/translations/Skv1982Aronia.html (accessed 30 May 2018).

Skvortsov A.K., Maitulina Yu.K., Gorbunov Yu.N. (1983). Cultivated black-fruited aronia: place, time, and probable mechanism of formation. Available at : http://www.salicicola.com/translations/Skv1983Aronia.html (accessed 30 May 2018).

Slimestad R., Torskangerpoll K., Nateland H.S., Johannessen T., Giske N.H. (2005). Flavonoids from black chokeberries, Aronia melanocarpa. Journal of Food Composition and Analysis 18(1): 61-68. https://doi.org/10.1016/j.jfca.2003.12.003

Taheri R. (2013). Polyphenol Composition of Underutilized Aronia Berries and Changes in Aronia Berry Polyphenol Content Through : dissertation theses. University of Connecticut. $126 \mathrm{p}$.

Valcheva-Kuzmanova S.V., Belcheva A. (2006). Current knowledge of Aronia melanocarpa as a medicinal plant. Folia Med (Plovdiv) 48(2): 11-17. https://doi.org/10.1016/j.jff.2014.03.004

Vinogradova Yu., Grygorieva O., Vergun O., Brindza J. (2017). Morphological characteristics for fruits of Aronia mitschurinii A.K. Skvortsov \& Maitul. Potravinarstvo Slovak Journal of Food Sciences 11(1): 754-760. https://doi.org/10.5219/845

Zeiner M., Juranović Cindrić I., Majić B., Stingeder G. (2017). Study of the accumulation of Toxic and Essential Ultra-Trace Elements in Fruits of Sorbus domestica L. International Journal of Environmental Research and Public Health 14 (4): E341. https://doi.org/10.3390/ijerph14040341 